Received December 14, 2017

Revised 1st, January 31, 2018

2nd, February 1, 2018

Accepted February 2, 2018

\author{
Corresponding author \\ Joung Goo Cho, M.D. \\ Department of Anesthesiology and \\ Pain Medicine, National Health \\ Insurance Service Ilsan Hospital, \\ 100 Ilsan-ro, Ilsandong-gu, Goyang \\ 10444, Korea \\ Tel: 82-31-900-0290 \\ Fax: 82-31-900-0114 \\ E-mail: anaper@naver.com \\ ORCID \\ http://orcid.org/0000-0001-5720-4264
}

\section{"Spray-as-you-go" medical technique for awake intubation using a combination of an epidural catheter and the OptiScope in a patient with Ludwig's angina - A case report -}

\author{
Da Jeong Nam ${ }^{1}$, Joung Goo Cho', Sang Hwa Kang', and \\ Soojeong Kang ${ }^{2}$
}

1 Department of Anesthesiology and Pain Medicine, National Health Insurance Service Ilsan Hospital, Goyang, '2Department of Anesthesiology and Pain Medicine, Yonsei University College of Medicine, Seoul, Korea

A 73-year-old woman presented to the emergency department with submandibular pain and swelling. The patient was diagnosed to have Ludwig's angina, and she was planned to undergo urgent incision and drainage under general anesthesia. However, her physical examination revealed severe diffuse swelling extending from the bilateral submandibular spaces to the submental space and further down to the neck. As our view was blocked by the patient's neck swelling, we did not perform a regional anesthesia of the airway or a transtracheal block. Several non-invasive alternatives were considered. The "spray-as-you-go" technique was chosen, and it was performed using the OptiScope ${ }^{\circledR}$. However, the OptiScope did not have a working channel or syringe adaptor for the administration of the local anesthetic solution. To solve this problem, we combined the OptiScope with a 27-G tunneled epidural catheter $(100 \mathrm{~cm})$ for the administration of lidocaine and this combination made the awake intubation successful.

Key Words: Awake intubation, Difficult intubation, Epidural catheter, Ludwig's angina, OptiScope, Spray-as-you-go.

Difficult airway intubation is one of the most frequent causes of complications in the operating room; therefore, a difficult airway is always of a particular concern to an anesthesiologist [1]. Deep neck infection, oral and maxillofacial surgery, and facial trauma surgery are common causes of a difficult airway. A flexible fiber-optic intubation scope with an external video monitor was used in the past for intubation of a difficult airway; this medical technique is useful in patients whose tracheas are difficult to intubate [2]. However, the insertion of a tube over the flexible fiber-optic scope is technically difficult in some patients [3]; thus, video-assisted de- vices are regarded as one of the solutions for this problem [4]. With the advancement of medical technology, several types of video-assisted equipment have been developed for intubation. Video-assisted intubating stylets, such as the OptiScope ${ }^{\circledR}$ (Clarus Medical, USA), are increasingly being applied in difficult intubations due to their many advantages. First of all, compared to the flexible fiber-optic device, the OptiScope is easy to hand-carry. As it contains a built-in video monitor and rechargeable battery, there is no need of an additional screen, electrical wiring, or power source. Secondly, the OptiScope can be used to visualize the anatomical areas directly;

This is an Open Access article distributed under the terms of the Creative Commons Attribution Non-Commercial License (http://creativecommons.org/licenses/by-nc/4.0) which permits unrestricted non-commercial use, distribution, and reproduction in any medium, provided the original work is properly cited.

Copyright (c) the Korean Society of Anesthesiologists, 2018 
and the operator can share the images and case-based experiences with his or her assistants or supervisors. Thirdly, the OptiScope is simple to use and has a user-friendly interface; hence, its operation can be learnt more easily than that of the flexible fiber-optic intubation scope can be.

In this report, we describe a method of utilizing an epidural catheter for the administration of a local airway anesthetic in the performance of awake intubation using the OptiScope.

\section{CASE REPORT}

The patient agreed with reporting her medical case. We have reported and approved this case to the Institutional Review Board of the National health Insurance Service Hospital Clinical Reserch Center.

A 73-year-old woman $(160 \mathrm{~cm}, 68 \mathrm{~kg}$, body mass index $26.5 \mathrm{~kg} / \mathrm{m}^{2}$ ) presented to the emergency department with submandibular pain and swelling. The patient, who had a past medical history of type 2 diabetes mellitus and reported no other co-morbidities, was classified to be in the American Society of Anesthesiologists physical status classification II. However, her physical examination revealed a severe diffuse swelling extending from the bilateral submandibular spaces to the submental space and further down to the neck; the swelling was erythematous, indurated, warm, and severely tender. Computed tomography scan of the neck showed heterogeneous (size, $6 \times 4 \times 3 \mathrm{~cm}$ in the left carotid space [A] and retropharyngeal space $[\mathrm{B}])$ retropharyngeal and parapharyngeal abscesses and necrotizing fasciitis (Fig. 1).

The patient was diagnosed to have Ludwig's angina and planned for urgent incision and drainage under general anesthesia. Although the assessment of the patient's airway was not performed adequately due to her neck swelling, the preoperative airway assessment of the patient demonstrated that the mouth opening was less than 2 fingerbreadths, forward jaw thrust was restricted (similar to that in Mallampati Class II), thyromental distance was less than $6 \mathrm{~cm}$, and there was mild restriction of the neck movements due to the neck
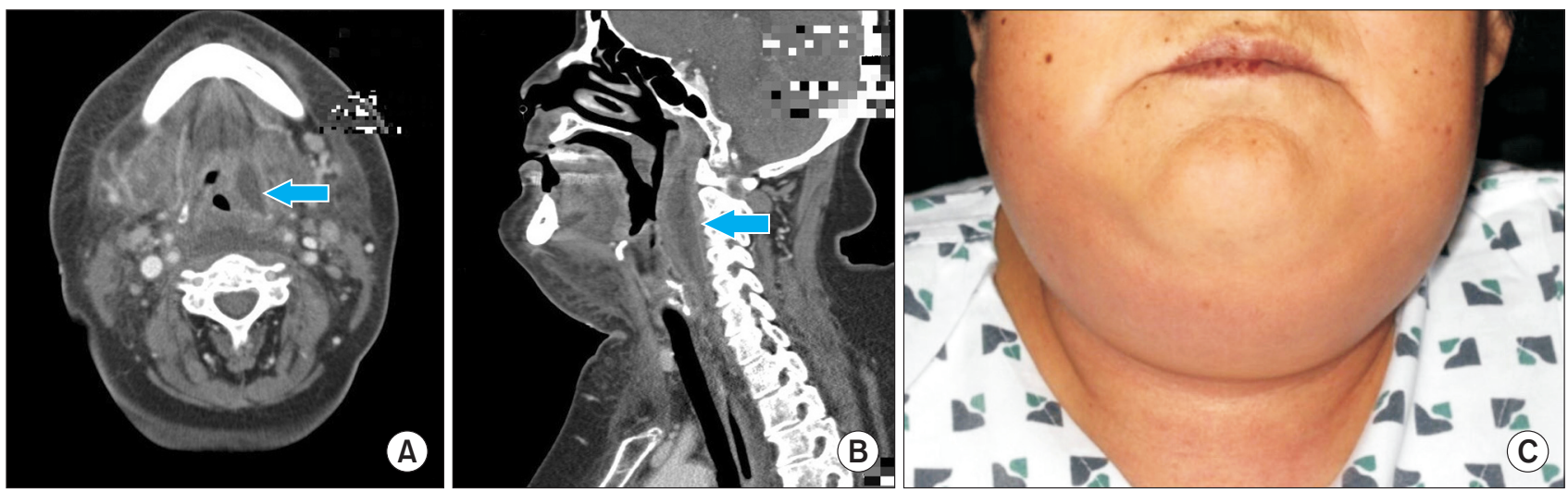

Fig. 1. Contrast-enhanced computed tomography scan of the neck showed a well-defined longitudinally oval, heterogeneously enhancing soft tissue lesion $(6 \times 4 \times 3 \mathrm{~cm})$ in the left carotid space $(\mathrm{A})$ and retropharyngeal space (B) extending longitudinally between $\mathrm{C} 1$ and $\mathrm{C} 4$. The patient was diagnosed to have Ludwig's angina (C).
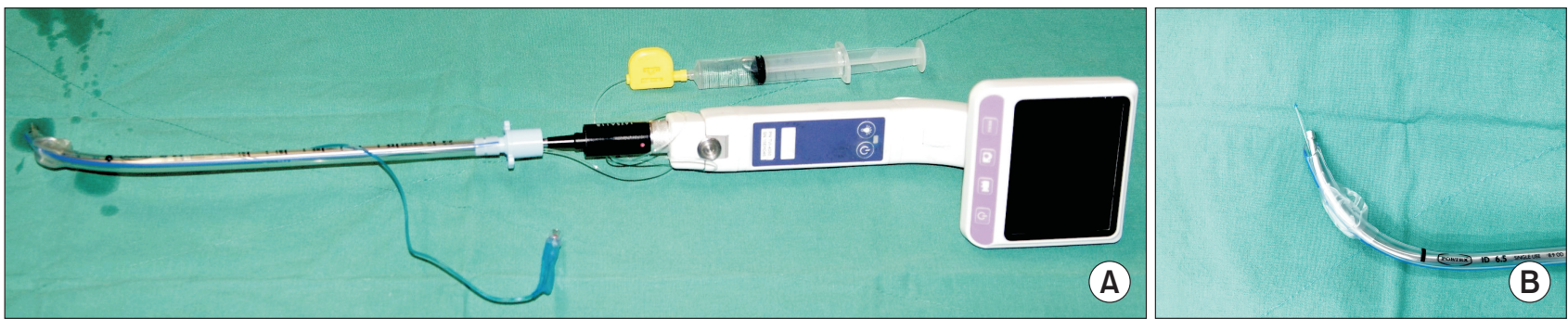

Fig. 2. The OptiScope ${ }^{\circledR}$ (Clarus Medical, USA) was prepared for the "spray-as-you-go" awake intubation. A cutting epidural catheter (100 cm) (Portex ${ }^{\circledR}$, Smiths Medical Ltd., Australia) was inserted into the endotracheal tube (A). The picture was taken to demonstrate the structures of the catheter and endotracheal tube. A tip of the epidural catheter was cut and the end of the catheter was not left poking out of the endotracheal tube (B). 
swelling and pain. Moreover, the computed tomography examination showed that the sub-glottis was narrowed by the surrounding abscesses; and the preoperative laryngoscopic evaluation revealed a focal bulge arising from the retropharynx. The bulge was just above the level of the glottis. Nevertheless, the patient was fully conscious and had no dyspnea. We decided to perform awake intubation using the OptiScope (Fig. 2) after a consideration of several choices. We thought that this method might be safe, although the patient was conscious and alert, it was difficult to keep our view and spaces to neck swelling and mass if we used muscle relaxants.

Owing to the blockage of our view by the patient's neck swelling, we could not choose a regional anesthesia of the airway or transtracheal block, therefore, several non-invasive alternatives were considered. Consequently, the "sprayas-you-go" local anesthesia method was performed [5,6]. However, the OptiScope did not have a working channel or syringe adaptor for the administration of the local anesthetic solution. Therefore, we decided to combine a tunneled epidural catheter with the OptiScope in order to apply lidocaine, which was used as a local anesthetic solution.

A 27-G cutting epidural catheter $(100 \mathrm{~cm})\left(\right.$ Portex $^{\circledR}$, Smiths Medical Ltd., Australia) was inserted into the internal diameter of a 6.5-mm endotracheal tube lumen on the OptiScope for the administration of lidocaine. The tip of the cutting epidural catheter was located at the end of the endotracheal tube to avoid damaging of the epiglottis and other tracheal areas; a syringe with the regional anesthetic was placed on the other side of the tip. The exact position of the tip of the cutting epidural catheter was changed constantly through the built-in video monitor of the OptiScope during intubation, and lidocaine was effectively applied on the vocal cords (Fig. 3).

The patient was in a supine position before the administration of anesthesia. She was administered an intravascular injection of glycopyrrolate $(0.1 \mathrm{mg})$ as a premedication. While undergoing monitoring with an invasive arterial pressure monitor, pulse oximetry, and an electrocardiogram, the patient was administered $100 \%$ oxygen $(6 \mathrm{~L} / \mathrm{min})$ via nasal prongs and remifentanil $(0.05 \mu \mathrm{g} / \mathrm{kg} / \mathrm{min})$ intravenous infusion over 10 minutes.

We used the $10 \%$ xylocaine spray to prevent nausea and vomiting into her mouth and throat due to the procedural stimulation. The patient's blood pressure was 128/68 mmHg; heart rate, 71 beats/min; and oxygen saturation, $100 \%$. After oral suctioning, the OptiScope was inserted into the patient's throat through the mouth, and its video monitor aided the visualization of the opening of the epiglottis and vocal cords. Then, $2 \%$ lidocaine ( $3 \mathrm{ml}$ ) was administered below the glottis through the tip of the epidural catheter to anesthetize the mucosa of the epiglottis; this helped to prevent pain, nausea, and vomiting into her mouth and throat. At this moment, the patient did not have a cough or gag reflex, and arterial blood pressure was 118/61 mmHg; heart rate, 66 beats/min; and oxygen saturation, 99\%. After 10 minutes, the OptiScope was inserted into the patient's throat to visualize the trachea. Then, an endotracheal tube was inserted into her trachea; the position of the endotracheal tube was confirmed by auscultation and end-tidal capnography. The OptiScope and epidural catheter were then removed; the patient's blood pressure was 129/71 mmHg; heart rate, 73 beats/min; and oxygen saturation, $99 \%$. We subsequently decided to administer a general anesthetic; therefore, the patient was administered $120 \mathrm{mg}$ of propofol intravenously. After confirming the loss of spontaneous breathing, we administered an intravascular injection of rocuronium bromide $(50 \mathrm{mg})$. The general anesthesia was maintained with sevoflurane and remifentanil $(0.07 \mu \mathrm{g} / \mathrm{kg} /$ $\min )$.

It took less than 15 minutes to complete the awake intubation, excluding the time for monitoring of vital signs and administering oxygen through the nasal prongs. In total, it took around 20 minutes, including the time for the pre-oxy-

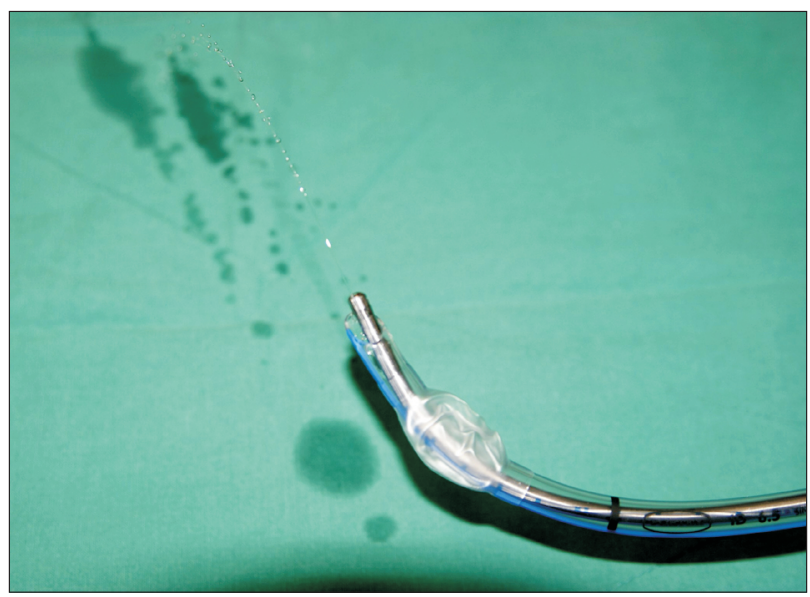

Fig. 3. 2\% Lidocaine was administered below the glottis through the tip of the epidural catheter to anesthetize the mucosa of the epiglottis and vocal cords to prevent the gag reflex, cough, pain, nausea, and vomiting into her mouth and throat. 
genation. The patient remained stable throughout the awake intubation: her blood pressure was stable, oxygen saturation was kept over 97\%, and there was no medical complication. Furthermore, there was no complication linked to the airway management. Although the operation was risky, it was carried out successfully. After the operation, the patient was moved to intensive care unit while still under intubation.

\section{DISCUSSION}

Ludwig's angina is characterized by a rapidly progressive gangrenous cellulitis of the soft tissues of the neck and floor of the mouth [7]. Therefore, a patient with Ludwig's angina should be considered to potentially have a difficult airway; this is because their airway anatomy is frequently distorted. If the disease progresses rapidly, it can pose a serious risk of sudden death due to airway obstruction. Thus, a special medical attention with regard to the time limit and method of intubation is required [8-10].

Generally, a flexible fiber-optic intubation scope with an external video monitor has been regarded as the standard in the management of an anticipated difficult airway. However, this technique has several disadvantages, such as high cost, unavailability, and poor durability. It is also a difficult technique to learn for effective usage. There are journal reports of failed tracheal intubation despite successful insertion of the fiber-optic scope into the trachea. Moreover, many anesthesiologists are unfamiliar with the fiber-optic scope; and it can fail in the management of a difficult airway $[11,12]$.

In contrast, the video-assisted devices are more affordable and portable; and they have manuals that are much easier to learn for the operation of the equipment. As a result, the updated guideline of the American Society of Anesthesiologists introduced a video-assisted intubating stylet for airway management in 2013 [13]. The guideline suggested that the choice of particular technique would depend on specific needs, preferences, skills, and clinical constraints.

In this case, the OptiScope was chosen for awake intubation because the patient had Ludwig's angina. Its reusable semi-rigid stylet, handle, and video screen help to avoid potentially traumatic airway manipulation during intubation. Moreover, its semi-rigid stylet can assist in overcoming the resistance of oropharyngeal soft tissues and prevent unintended movement of oral structures. However, the OptiScope does not have any port or syringe adaptor for the administration of a local anesthetic solution; therefore, a combination of a tunneled epidural catheter with the OptiScope was used to apply lidocaine. Following this operation, we have had successful results in similar cases.

In this case, unlike the suction catheter, the epidural catheter can be connected to a syringe with lidocaine through its proximal sleeve. Furthermore, using the epidural catheter for airway topicalization with the "spray-as-you-go" technique can help to overcome the demerit of the OptiScope, which is a lack of a working channel for the administration of local anesthetics.

In conclusion, we suggest that a combination of an epidural catheter and a video-assisted intubating stylet such as the OptiScope as an alternative solution for the problems of managing a difficult airway. It allows effective and accurate airway topicalization in patients.

\section{REFERENCES}

1. Iqbal R, Kapila A. Difficult airway: definitions, incidence and consequences. In: Difficult airway management. Edited by Popat MT: Oxford, Oxford University Press. 2009, pp 1-10.

2. Gil KSL, Diemunsch PA. Flexible scope intubation techniques. In: Hagberg and Benumof's airway management. 4th ed. Edited by Hagberg CA, Artime CA, Aziz MF: Philadelphia, Elsevier. 2018, pp 428-70.

3. Maktabi MA, Hoffman H, Funk G, From RP. Laryngeal trauma during awake fiberoptic intubation. Anesth Analg 2002; 95: 1112-4.

4. Finucane BT, Tsui BCH, Santora AH. Principles of airway management. 4th ed. New York, Springer. 2011, pp 548-50.

5. Sethi N, Tarneja VK, Madhusudanan TP, Shouche S. Local anaesthesia for fiberoptic intubation: a comparison of three techniques. Med J Armed Forces India 2005; 61: 22-5.

6. Mushambi MC, Pandey R. Management of the difficult airway in the obstetric patient. In: Oxford textbook of obstetric anaesthesia. Edited by Clark V, de Velde MV, Fernando R: Oxford, Oxford University Press. 2016, pp 393-418.

7. Candamourty R, Venkatachalam S, Babu MR, Kumar GS. Ludwig's angina - an emergency: a case report with literature review. J Nat Sci Biol Med 2012; 3: 206-8.

8. Saifeldeen K, Evans R. Ludwig's angina. Emerg Med J 2004; 21 : 242-3.

9. Kulkarni AH, Pai SD, Bhattarai B, Rao ST, Ambareesha M. Ludwig's angina and airway considerations: a case report. Cases J 2008; $1: 19$. 
10. Pedigo RA, Amsterdam JT. Oral medicine. In: Rosen's emergency medicine: concepts and clinical practice. 9th ed. Edited by Walls RM, Hockberger RS, Gausche-Hill M: Philadelphia, Elsevier. 2017, pp 771-89.

11. Hagberg C, Artime C. Airway Management in the Adult. In: Miller's anesthesia. 8th ed. Edited by Miller RD, Cohen NH, Eriksson LI, Fleisher LA, Wiener-Kronish JP, Young WL: Philadelphia, Elsevier/Saunders, cop. 2015, pp 1647-83.
12. Frerk C, Mitchell VS, McNarry AF, Mendonca C, Bhagrath R, Patel A, et al. Difficult airway society 2015 guidelines for management of unanticipated difficult intubation in adults. $\mathrm{Br} J$ Anaesth 2015; 115: 827-48.

13. Abramowicz AE, Bustillo M. Anesthesia for cervical spinal cord injury. In: Anesthesia for trauma: new evidence and new challenges. Edited by Scher CS: New York, Springer. 2014, pp 167-92. 